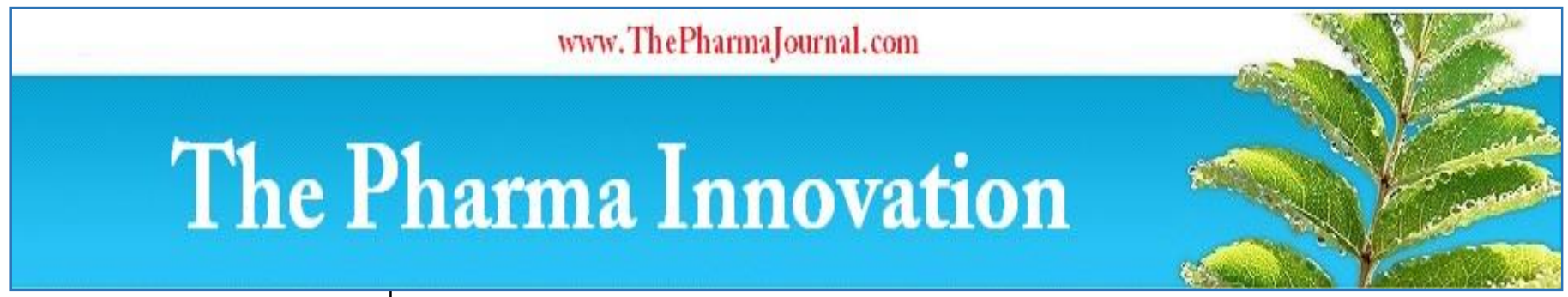

ISSN (E): 2277 - 7695

ISSN (P): 2349-8242

NAAS Rating: 5.23

TPI 2021; SP-10(3): 237-242

(C) $2021 \mathrm{TPI}$

www.thepharmajournal.com

Received: 23-01-2019

Accepted: 26-03-2019

\section{Abhishek Kumar}

Ex-M.Tech Research Scholar, Department of Farm Machinery and Power Engineering (FMPE) PAU, Ludhiana, Punjab, India

\section{Varinder Singh Saimbhi}

Extension Scientist, Department of Farm Machinery and Power Engineering (FMPE), PAU, Ludhiana, Punjab, India

\section{Jagjeet Singh}

PhD Research Scholar, Indian Agricultural Research Institute, Pusa, New Delhi, India

\section{Corresponding Author:} Abhishek Kumar

Ex-M.Tech Research Scholar, Department of Farm Machinery and Power Engineering (FMPE), PAU, Ludhiana, Punjab, India

\section{Effect of various tillage practices on pulverisation of different soil types}

\author{
Abhishek Kumar, Varinder Singh Saimbhi and Jagjeet Singh
}

DOI: https://doi.org/10.22271/tpi.2021.v10.i3Sd.6110

\begin{abstract}
A study for evaluating the soil pulverisation caused by different tillage practices, like harrow-cultivatorplanker, rotavator practice and spading tillage machine was undertaken in the fields. The experiment was carried out at the fields of two different soil types viz. sandy loam (S1) and silty loam (S2). Six tillage practices, designated as $\mathrm{P} 1, \mathrm{P} 2, \mathrm{P} 3, \mathrm{P} 4, \mathrm{P} 5$ and $\mathrm{P} 6$, were undertaken in the present study. The six practices were one pass of harrow-cultivator-planker combination (P1), two passes of harrow-cultivatorplanker combinations (P2), one pass of rotavator (P3), two passes of rotavator (P4), one pass of spading tillage machine (P5) and two passes of spading tillage machine (P6). Different implements have their own, i.e. different recommended speeds and depths of operation. For experimental study, two different depths of cut ranges, designated as D1 \& D2 and two forward velocity ranges, designated as V1 \& V2, suitable to every implement, were selected. The experiments have been laid out by using factorial in randomized block design, henceforth designated as $\mathrm{f}-\mathrm{RBD}$, of statistical methods to minimize variation of soil properties on the treatments. In order to find out the soil pulverisation caused by different tillage practices taken in the present study, each treatment was replicated three times. The mean weight diameter of soil clods formed after different tillage practices were found to be smaller in sandy loam soil as compared to silty loam soil.
\end{abstract}

Keywords: mean weight diameter, pulverisation, sieve analysis, tillage, cultivator, harrow, planker, rotavator, spading machine, sandy loam, silty loam

\section{Introduction}

Soil is a medium that provides most of the essential nutrients required for the plant growth. The availability of these nutrients determines fertility level of the soil. The soil fertility generally varies from place to place and time to time. However, the fertility of field soil can be improved by two ways, i.e. by tillage practices through the pulverization process and by adding inorganic and organic manures. The pulverization refers to the transformation of compacted textured soil to fine textured soil, by application of external forces using farm machineries such as rotavator, cultivator, harrow, etc. It helps to reduce the compaction of the surface field soil, that badly effects the root penetration and crop yield. There are many studies that showed the ill effects of soil compaction on crop yield (Borisov, 1985; Arvidsson and Hakansson, 1991; Keisling et al., 1995; Lipiec, et al., 2003; Schwab, et al., 2004; Filipovic, et al., 2006) ${ }^{[1-6]}$. In addition, pulverization also produces favourable field conditions for the plant growth by increasing water holding capacity, reducing soil temperature and increasing available nitrogen in the soil through the aeration process. The success of the crops highly depends on pulverization quality that can be achieved through various tillage practices in different soils. Hence, it becomes the need of the time to determine the best tillage practice in different types of soil, for the success of the crops on account of good quality of pulverization. Therefore, this research proposed under study was to quantify the effect of various tillage practices and soil types on pulverisation quality.

\section{Materials and Methods}

\section{Independent parameters of the study}

Different independent parameters were selected for determining its effect on soil pulverisation, caused due to different practices and the parameters that express pulverisation (mean weight clod diameter) are discussed as per following sub heads:

1. Soil type

2. Tillage practices

3. Forward velocity 


\section{Depth of operation}

\section{Soil type}

Field plots at two different locations of varied soil texture described henceforth as S1 and S2 were selected. The soil texture has been characterized by ascertaining the soil physical parameters. i.e. per cent sand, silt and clay. Soil samples were taken from at least four different locations of the selected plot i.e. from S1 and S2 separately. Samples taken from fields S1 and S2 were mixed separately and part of soil samples (S1 and S2) were taken to soil testing laboratory of the Department of Soil Science, Punjab Agricultural University, Ludhiana for analysis work.

\section{Tillage practices}

Three different tillage practices were taken for the present study and described as per following sub heads:

1. Conventional tillage practice

2. Tillage with rotavator

3. Tillage with spading machine

\section{a. Conventional tillage practice}

Three tillage implements, viz. disc-harrow, cultivator and planker, used commonly for conventional tillage were selected. All implements were operated once, one after the other i.e. first disc-harrow, then cultivator and then planker (one pass each) and this practice has been designated as P1. Another tillage practice has been considered for the present study by using two passes of each one after the other, of all the selected implements and designated as P2. The specific but brief information regarding the different implements has been given as follows:

A semi mounted double action disc harrow (Amsons) was used with 16 discs arranged on two gangs as shown in Figure 1. Mild steel angle welded frame structure was mounted on the individual gang of discs. Curved discs with plane sharp cutting edge were used. The disc harrow was hydraulically lifted for locomotion.

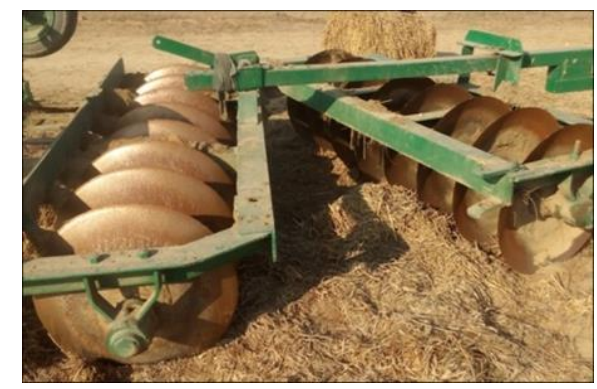

Fig 1: A stationary view of Disc harrow

An 11 Tyne cultivator with spring loaded tynes (Amsons) was used as shown in Figure 2. Heavy springs provide safety to the tynes against shock and impact loads encountered during field operations. Width of cultivator was $2.4 \mathrm{~m}$.

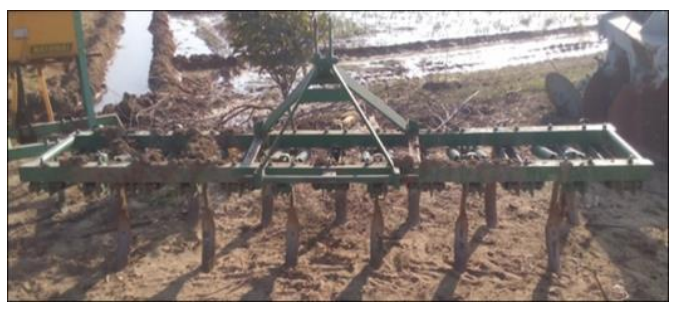

Fig 2: A stationary view of 11 Tyne cultivator
A mild steel planker of width $3 \mathrm{~m}$ (Amsons) was used for the top finishing operation of the soil shown in Figure 3.

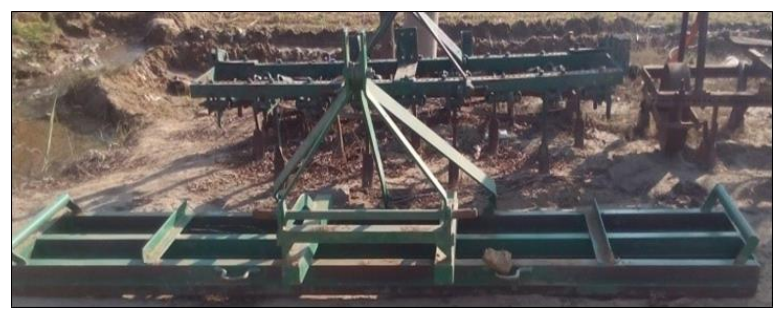

Fig 3: A stationary view of Planker

\section{b. Tillage with rotavator}

A horizontal shaft forward rotary rotavator with L-shaped blades has been used for the study. Two tillage practices of rotavator were taken in the study viz. one pass of rotavator designated as P3 and two passes of rotavator designated as P4. The specific but brief information about rotavator has been given. The rotavator (Dasmesh) used for the study comprises of 36 L-type blades, as shown in Figure 4. The rotavator was designed to operate at 540 PTO rpm and had a rotor speed of $270 \mathrm{rpm}$. Physical dimensions of the rotavator viz. width $\mathrm{x}$ height $\mathrm{x}$ length were $1.77 \mathrm{~m} \times 0.94 \mathrm{~m} \times 1.35 \mathrm{~m}$. Working width of the rotavator was $1.52 \mathrm{~m}$.

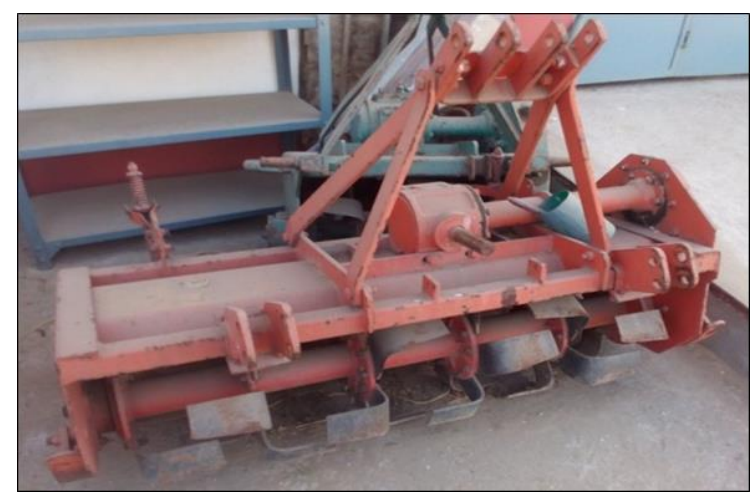

Fig 4: A stationary view of the rotavator with L type blades.

\section{c. Tillage with spading machine}

A spading machine (Selvatici, 150.75 series, 1105 model) having $1.1 \mathrm{~m}$ width has been used for the study. Two tillage practices of spading machine were taken i.e. one pass of spading machine designated as P5 and two passes of spading machine designated as P6. The spading machine manufactured by Bologna (Italy) based farm machinery manufacturing company. Selvatici was used in the present investigation as shown in Figure 5. This is a compact machine equipped with five spades and works on a width of $110 \mathrm{~cm}$. The depth of working has been adjustable up to a maximum of $30 \mathrm{~cm}$.

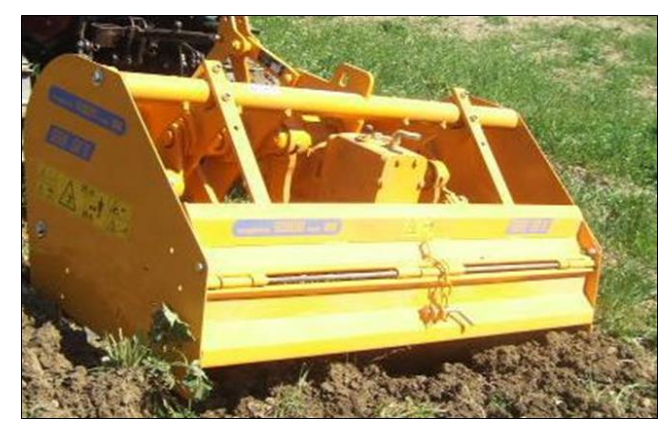

Fig 5: A view of spading machine used in the study 
Tractor selected in the experiment was JOHN DEERE $55 \mathrm{hp}$ equipped with a fuel flow meter as shown in Figure 6.

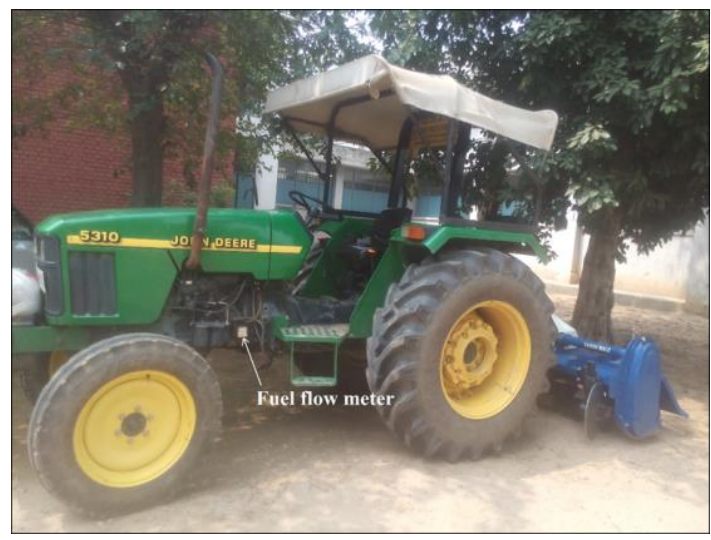

Fig 6: A view of tractor equipped with the fuel meter

\section{Forward velocity}

Two different ranges of forward velocities hence-forth described as V1 and V2, for the tillage implements has been taken. V1 has been taken as the lower manageable velocity range while V2 has been taken as the higher manageable velocity range. Appropriate velocity ranges have been selected so that all implements could confirm the selected ranges. The forward velocity of implements was measured by standard velocity measurement relationship given in equation 1.

$\mathrm{v}=\mathrm{d} / \mathrm{t}$

Where,

$\mathrm{v}=$ forward speed, $\mathrm{m} / \mathrm{s}$

$\mathrm{d}=$ distance in meters, $\mathrm{m}$

$\mathrm{t}=$ time taken to cover the designated distance in seconds.

\section{Depth of operation}

Two different depth ranges, henceforth described as D1 and D2, for operating each of the tillage implements has been taken. The shallower depth range has been designated as D1 and the deeper depth range of operation as D2. The required depth of operation was maintained by the hydraulic control of lower links and the top link adjustment of three-point linkage system of tractor. Test runs were conducted for the depth adjustment of different implements before actual experimental runs. Appropriate depth ranges have been selected so that all implements could confirm the selected ranges. A ruler $(30 \mathrm{~cm}$ length) with a least count of $1 \mathrm{~mm}$, was used to measure the depth of operation of various implements, as shown in Figure 7.

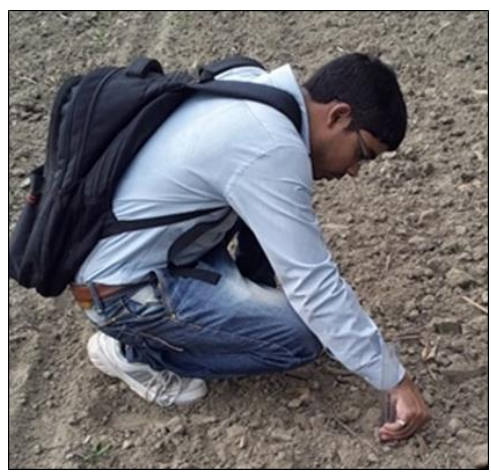

Fig 7: A view of depth of operation measurement using a ruler

\section{Dependent parameter of the study 1. Mean weight diameter of soil clods}

The mean weight diameter, henceforth described as MWD, of the soil aggregates have been considered as index of soil pulverization caused by different tillage practices, considered under the present study. The degree of soil pulverization was measured by determining the MWD of soil clods after tillage practices by using sieve analysis technique. For this, sieves of appropriate mesh sizes were selected to assess the degree of pulverization. A set of 10 sieves of different sizes $(75,19,8$, $4.75,2.8,2,1,0.6,0.425$ and $0.15 \mathrm{~mm}$ ) were used with size decreasing downwards up to the pan. The sieve set consisted of sieve sizes according to BIS standards IS 2720-4 (1985). After performing different tillage practices, samples were drawn in three replications randomly, using soil sampler (length:150 mm x width:150 mm x height:300 mm) as shown in figure 8 . The soil samples were shade dried for 24 hours before carrying out the sieve analysis. The sieve analysis was done by using mechanical sieve shaker, as shown in figure 9 . The weighted mean of the soil restrained in different sieves was found. The weight of soil retained by each sieve was also noted down. The mean weight diameter of soil clods formed due to the tillage treatments were calculated by using equation 2 .

$\mathrm{MWD}=\left(\sum \mathrm{W}_{\mathrm{i}} * \mathrm{~d}_{\mathrm{i}}\right) / \mathrm{W}_{\mathrm{T}}$

Where,

$\mathrm{d}_{\mathrm{i}}=$ average diameter of $\mathrm{i}$ and $(\mathrm{i}+1)^{\text {th }}$ sieve in $\mathrm{mm}$, such that $\mathrm{d}_{\mathrm{i}}<\mathrm{d}_{\mathrm{i}+1}$,

$\mathrm{W}_{\mathrm{i}}=$ weight of soil retained on the $\mathrm{i}^{\text {th }}$ sieve in $\mathrm{gm}$,

$\mathrm{W}_{\mathrm{T}}=$ total weight of soil sample in gm.

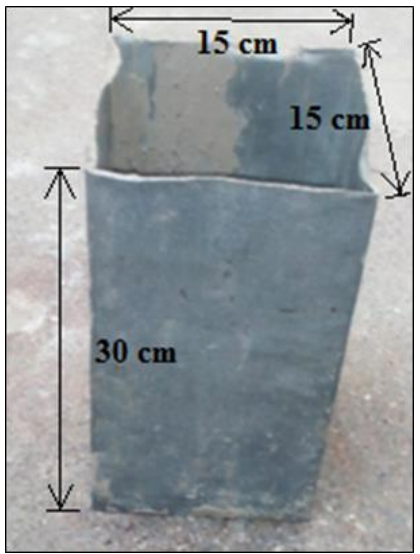

Fig 8: A view of the soil sampler used for MWD determination

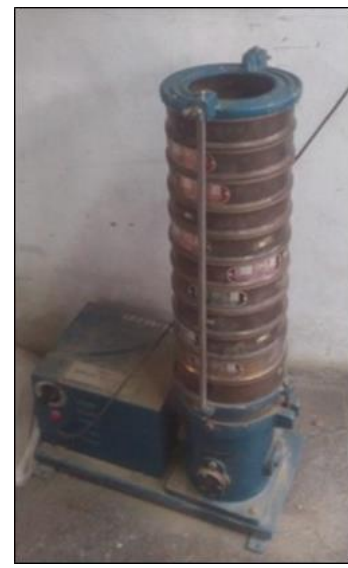

Fig 9: A view of the sieve shaker 


\section{Layout of experimental plots}

The experiments had been laid out by using factorial in randomized block design, henceforth designated as f-RBD, of statistical methods to minimize the effect of varying soil properties on the treatments. In order to find out the soil pulverisation caused by different tillage practices taken in the present study, each treatment was replicated three times.

Paper chits with the name of different treatments were prepared by writing designated tillage practices, forward velocities and depth of operations as factors. The paper chits were thoroughly mixed and random draw of lot was performed one by one till the end of lot. Then, accordingly the names of the treatments were written for one block. This process was repeated for a total of six times for the two soils, each comprising of three randomized blocks i.e. three replications.

\section{Statistical analysis}

Different statistical methods have been formulated to quantify the soil pulverisation affected by different tillage practices adopted in the present study. Factorial in randomized block design (f-RBD) was formulated on soil types, tillage practices, forward speeds and depths of cut as independent parameters. Analysis of variance in f-RBD was performed to show the significance of each parameter. Dependent variable i.e. pulverization in terms of MWD of soil clods in terms of their respective general means were compared on the basis of the tests.

\section{Results and Discussion}

\section{Layout of experimental plots}

The experiments were laid on fields of research farms of Department of farm machinery and power engineering, Punjab Agricultural University (PAU), Ludhiana. The fields were demarcated as per the experimental layout. The two soil types were divided into 24 plots for the tillage treatments. Length of run was $27 \mathrm{~m}$ and $25 \mathrm{~m}$ for $\mathrm{S} 1$ and $\mathrm{S} 2$, respectively.

\section{Independent parameters of the study}

Different operating ranges were selected for different independent parameters depending upon nature of tillage implements used in the present study.

\section{a. Soil type}

The soil samples of two different sites, selected for the experimentation, were analyzed for particle size distribution (soil texture). The $\mathrm{S} 1$ soil composes of $76 \%$ sand, $12 \%$ silt and $12 \%$ clay, hence termed as sandy loam texture whereas S2 soil composes $20 \%$ sand, $55 \%$ silt and $25 \%$ clay, hence falls under silty loam texture.

\section{b. Tillage practices}

Six different tillage practices, viz.

1. One pass each of harrow followed by cultivator and planker (P1),

2. Two passes each of harrow followed by cultivator and planker $(\mathrm{P} 2)$,

3. One pass of rotavator $(\mathrm{P} 3)$,

4. Two passes of rotavator (P4),

5. One pass of spading machine (P5) and

6. Two passes of spading machine (P6), were considered for the present study.

Therefore, a total of five different tillage implements were used for the experimental study.

\section{c. Forward velocity}

All the implements have their own recommended speed of operation. For experimental study, two different forward speed ranges, suitable to every implement, were selected. The lower speed range (V1) of all tillage implements was maintained between $1.63 \mathrm{~km} / \mathrm{h}$ to $5 \mathrm{~km} / \mathrm{h}$. The lower speed of operation in the conventional tillage practices $\mathrm{P} 1$ and $\mathrm{P} 2$, disc harrow, cultivator and planker was operated at about 3.9-5 $\mathrm{km} / \mathrm{h}$, in practices $\mathrm{P} 3$ and $\mathrm{P} 4$, rotavator was operated at about $1.63-2.46 \mathrm{~km} / \mathrm{h}$. For practices P5 and P6, spading machine was operated at about $1.92-2.31 \mathrm{~km} / \mathrm{h}$.

The higher speed range (V2) of all tillage implements were maintained between $2.37 \mathrm{~km} / \mathrm{h}$ to $7.47 \mathrm{~km} / \mathrm{h}$. In the conventional tillage practice $\mathrm{P} 1$ and $\mathrm{P} 2$, disc harrow, cultivator and planker was operated at about $5.4-7.47 \mathrm{~km} / \mathrm{h}$, in practices $\mathrm{P} 3$ and $\mathrm{P} 4$, rotavator was operated at about 2.37 $2.85 \mathrm{~km} / \mathrm{h}$ and in practices P5 and P6, spading machine was operated at about $2.5-3 \mathrm{~km} / \mathrm{h}$.

\section{d. Depth of operation}

Similarly, different implements have different depth of operation. For the experimental study, two different ranges of depth of operation were selected. The shallower depth range of operation (D1) maintained for the selected implements, were between $5 \mathrm{~cm}$ to $10 \mathrm{~cm}$. For the lower depth, the conventional tillage practices $\mathrm{P} 1$ and $\mathrm{P} 2$, disc harrow, cultivator and planker was operated at about $10 \mathrm{~cm}$, in practices $\mathrm{P} 3$ and $\mathrm{P} 4$, rotavator was operated at about $5 \mathrm{~cm}$ and in practices $\mathrm{P} 5$ and $\mathrm{P} 6$, spading machine was operated at about $5 \mathrm{~cm}$.

The deeper depth ranges of operation (D2) were maintained between $10 \mathrm{~cm}$ to $15 \mathrm{~cm}$ for all the implements under study. For the deeper depth, the conventional tillage practices P1 and $\mathrm{P} 2$, disc harrow, cultivator and planker was operated at about $15 \mathrm{~cm}$, in practices $\mathrm{P} 3$ and $\mathrm{P} 4$, rotavator was operated at about $10 \mathrm{~cm}$ and in practices P5 and P6, spading machine was also operated at about $10 \mathrm{~cm}$.

\section{Dependent parameter of the study Mean weight diameter (MWD) of soil clods}

Mean weight diameter of soil clods was determined using equation 2. The average values of mean weight diameter of soil clods observed, after different tillage practices are given in Table 1.

Table 1: Effect of tillage practices, forward speed and depth of operation on mean weight diameter (MWD) of soil clods in soil S1 and soil S2

\begin{tabular}{|c|c|c|c|}
\hline \multirow{2}{*}{ Sr. No. } & \multirow{2}{*}{ Treatment } & \multicolumn{2}{|c|}{ Average mean weight diameter of soil clods, mm } \\
\cline { 3 - 4 } & & Soil S1 & Soil S2 \\
\hline 1. & P1V1D1 & 4.91 & 13.01 \\
\hline 2. & P1V1D2 & 3.44 & 28.72 \\
\hline 3. & P1V2D1 & 7.65 & 33.04 \\
\hline 4. & P1V2D2 & 7.24 & 39.56 \\
\hline
\end{tabular}




\begin{tabular}{|c|c|c|c|}
\hline 5. & P2V1D1 & 3.52 & 28.72 \\
\hline 6. & P2V1D2 & 4.49 & 22.39 \\
\hline 7. & P2V2D1 & 5.86 & 24.93 \\
\hline 8. & P2V2D2 & 6.17 & 29.85 \\
\hline 9. & P3V1D1 & 2.36 & 10.48 \\
\hline 10. & P3V1D2 & 2.66 & 23.04 \\
\hline 11. & P3V2D1 & 2.51 & 13.21 \\
\hline 12. & P3V2D2 & 4.02 & 11.30 \\
\hline 13. & P4V1D1 & 2.01 & 8.98 \\
\hline 14. & P4V1D2 & 3.26 & 12.14 \\
\hline 15. & P4V2D1 & 5.89 & 10.01 \\
\hline 16. & P4V2D2 & 2.71 & 10.99 \\
\hline 17. & P5V1D1 & 3.96 & 15.44 \\
\hline 18. & P5V1D2 & 6.90 & 19.41 \\
\hline 19. & P5V2D1 & 10.56 & 22.08 \\
\hline 20. & P5V2D2 & 4.09 & 14.59 \\
\hline 21. & P6V1D1 & 4.58 & 16.70 \\
\hline 22. & P6V1D2 & 6.84 & 12.37 \\
\hline 23. & P6V2D1 & 11.82 & 16.61 \\
\hline 24. & P6V2D2 & 6.81 & 15.86 \\
\hline
\end{tabular}

The MWD of soil clods after different tillage practices was found to be between $2.01 \mathrm{~mm}$, for tillage practice $\mathrm{P} 4$ at velocity V1 and depth $\mathrm{D} 1$, to $11.82 \mathrm{~mm}$, for tillage practice P6 at velocity V2 and depth D1 in soil S1. For soil S2, it was found to vary between $8.98 \mathrm{~mm}$, for tillage practice $\mathrm{P} 4$ at velocity V1 and depth $\mathrm{D} 1$, to $39.56 \mathrm{~mm}$, for tillage practice P1 at velocity V2 and depth D2. The lower MWD in soil S1, may be due to the fact that sandy loam soil gets easily pulverized because of lesser binding forces between the soil particles whereas in case of silty loam soil, the binding forces are more and does not get pulverized easily hence resulting in bigger clods.

The analysis of variance (ANOVA) of mean weight diameter (MWD) values for all tillage practices, at given forward velocities and depths of cut ranges for selected soil types, is given in Table 2.

Table 2: ANOVA for mean weight diameter (MWD) values

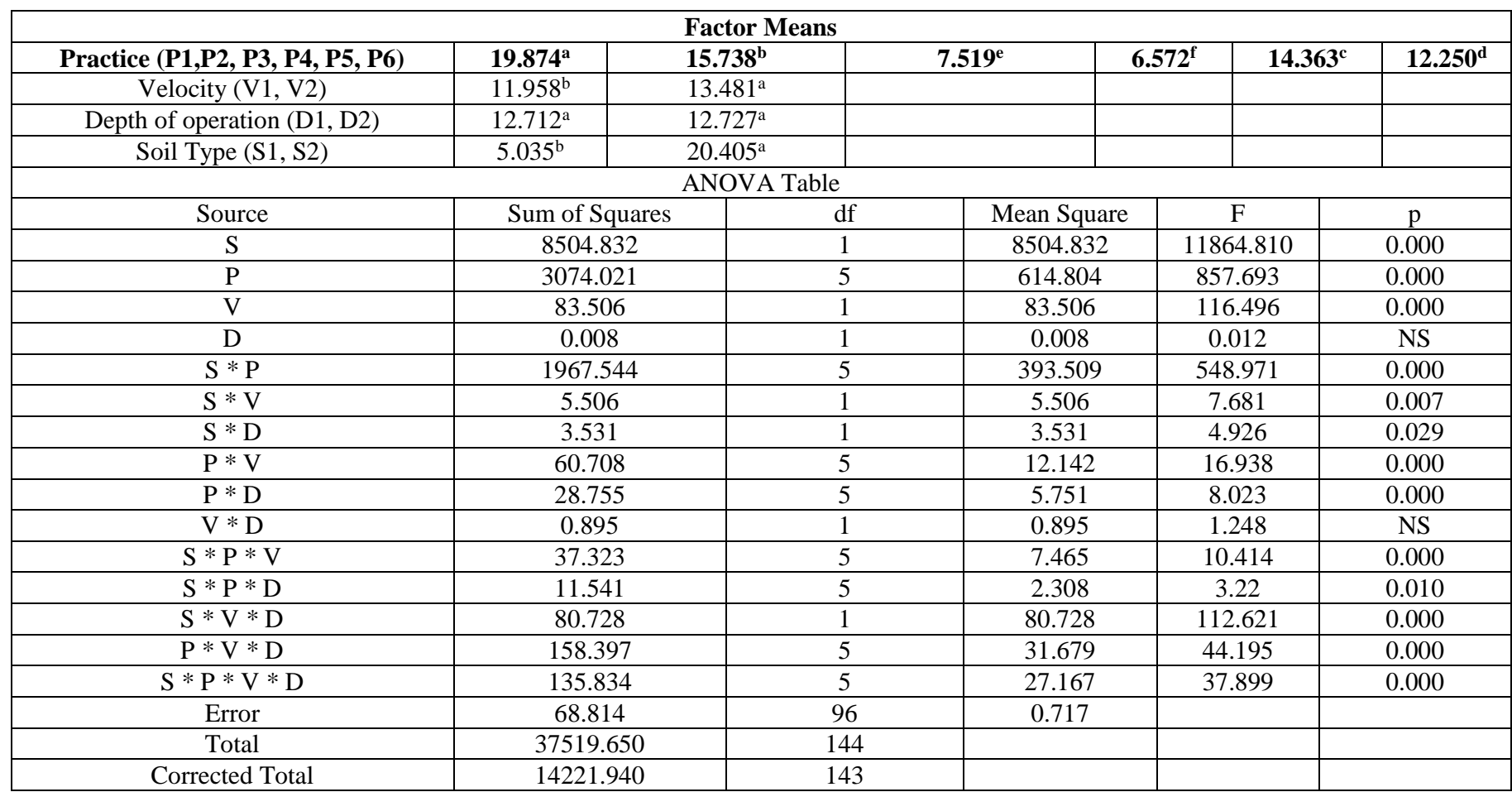

Tukey's test has been applied to see the difference in mean weight diameter values. Figures with different superscripts are found to be significantly different $(p<0.05)$.

The ANOVA for mean weight diameter (MWD) values were found to be statistically significant for the factors of tillage practices, soil types and velocity and non-significant for depth of operation ranges. All the factor interactions were found to be statistically significant for variation in mean weight diameter (MWD) values except for the factor interaction of velocity and depth of cut.

\section{Conclusions}

A study for evaluating the soil pulverisation caused by different tillage practices, like harrow-cultivator-planker, rotavator practice and spading tillage machine was undertaken in the fields. The experiment was carried out at the fields of two different soil types viz. sandy loam (S1) and silty loam (S2). Six tillage practices, designated as P1, P2, P3, P4, P5 and P6, were undertaken in the present study. The six 
practices were one pass of harrow-cultivator-planker combination (P1), two passes of harrow-cultivator-planker combinations (P2), one pass of rotavator (P3), two passes of rotavator $(\mathrm{P} 4)$, one pass of spading tillage machine (P5) and two passes of spading tillage machine (P6). Different implements have their own, i.e. different recommended speeds and depths of operation. For experimental study, two different depths of cut ranges, designated as D1 \& D2 and two forward velocity ranges, designated as V1 \& V2, suitable to every implement, were selected. The experiments have been laid out by using factorial in randomized block design, henceforth designated as f-RBD, of statistical methods to minimize variation of soil properties on the treatments. In order to find out the soil pulverisation caused by different tillage practices taken in the present study, each treatment was replicated three times. The mean weight diameter of soil clods formed after different tillage practices were found to be smaller in sandy loam soil as compared to silty loam soil.

\section{Acknowledgment}

I, Abhishek Kumar, want to thank my mother, Anita Sharan, who's non ending wishes and moral support stood firm with me throughout in all the diversified situations of life.

I also want to thank my MTech advisor, Dr. Varinder Singh Saimbhi, who maintained a lot of patience and endurance, and helped me during my tough times of the master's degree programme.

\section{References}

1. Borisov G. Effect of soil compaction caused by a UMZ tractor on the yield of wheat. Soil Science, Agro chemistry and Plant Protection 1985;20(3):78-86.

2. Arvidsson J, Håkansson I. A model for estimating crop yield losses caused by soil compaction. Soil Till. Res 1991;20:319-332.

3. Keisling TC, Batchelor JT, Porter OA. Soybean root morphology in soils with and without tillage pans in the lower Mississippi River valley. Journal of Plant Nutrition 1995;18:373-384.

4. Lipiec J, Medvedev VV, Birkas M, Dumitru E, Lyndina TE, Rousseva S, Fulajtar E. Effect of soil compaction on root growth and crop yield in Central and Eastern Europe. International agrophysics 2003, 17(2).

5. Schwab GJ, Murdock LW, Wells LG. Assessing and preventing soil compaction in Kentucky. University of Kentuky, College of Agriculture 2004, 5(5).

6. Filipovic D, Husnjak S, Kosutic S, Gospodaric Z. Effects of tillage systems on compaction and crop yield of Albic Luvisol in Croatia. Journal of Terramechanics 2006;43(2):177-189. 